\title{
Automated analysis of carbon in powdered geological and environmental samples by Raman Spectroscopy
}

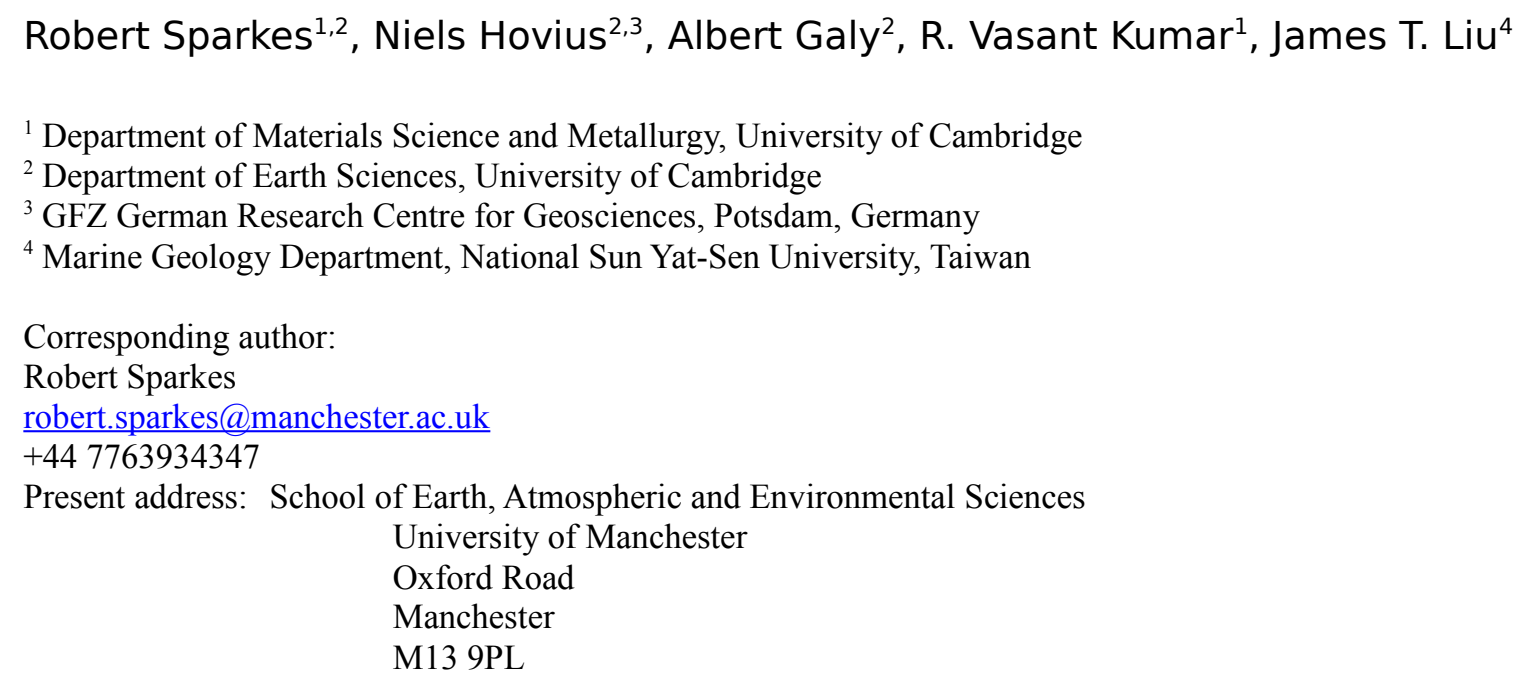

Other authors:

hovius@gfz-potsdam.de

albert00@esc.cam.ac.uk

rvk10@,cam.ac.uk

james@,facmail.nsysu.com.tw

\section{Abstract}

Raman Spectroscopy can be used to assess the structure of naturally occurring carbonaceous materials (CM), which exist in a wide range of crystal structures. The sources of these geological and environmental materials include rocks, soils, river sediments and marine sediment cores, all of which can contain carbonaceous material ranging from highly-crystalline graphite to amorphouslike organic compounds. In order to fully characterise a geological sample and its intrinsic heterogeneity, several spectra must be collected and analysed in a precise and repeatable manner. Here we describe a suitable processing and analysis technique. We show that short-period ball-mill grinding does not introduce structural changes to semi-graphitized material and allows for easy collection of Raman spectra from the resulting powder. Two automated peak 
fitting procedures are defined which allow for rapid processing of large datasets. For very disordered CM, Lorentzian profiles are fitted to five characteristic peaks, for highly-graphitized material three Voigt profiles are fitted. Peak area ratios and peak width (FWHM) measurements are used to classify each spectrum and allow easy comparison between samples. By applying this technique to samples collected in Taiwan following typhoon Morakot, sources of carbon to offshore sediments have been identified. Carbon eroded from different areas of Taiwan can be seen mixed together and deposited in the offshore flood sediments, and both graphite and amorphous-like carbon have been recycled from terrestrial to marine deposits. The practicality of this application illustrates the potential for this technique to be deployed to sediment sourcing problems in a wide range of geological settings.

\section{Keywords: Taiwan, Raman Spectroscopy, Sediment,} Graphite, Typhoon Morakot, Grinding, Organic Carbon,

\section{Kerogen}




\section{Introduction}

Raman Spectroscopy is a precise tool for analysing the structure of carbonaceous material in geological,1.2 biogeochemical3 and environmental samples. 4 The method targets individual carbon particles that can be finely dispersed, with variable structural ordering, making the measurement of a large number of spectra for a given sample a prerequisite for robust interpretation. Established methods acquire Raman spectra from thin sections, by passing the incident light through an overlying transparent mineral onto a carefully aligned graphite crystal, or directly from raw sediment grains or powders. This is followed by manual peak fitting of the collected data, which is time-consuming and limits the rate of work. This is not a problem for metamorphic studies, where only a few spectra are required, but hundreds or thousands of different spectra may be collected when analysing sedimentary rocks. Here we describe methods of sample preparation and peak fitting which facilitate rapid acquisition of Raman spectra and analysis of carbon structure for the benefit of geological and environmental applications. This involves short-period ball-mill grinding of solid rock or sediments which releases carbonaceous material without introducing structural changes, and automated peak fitting permitting objective analysis and comparison of many spectra without requiring manual intervention, yet allowing for checking of individual fitting results.

Whilst crystalline graphite is the thermodynamically stable form of carbon in the Earth's lithosphere, 5 its formation is kinetically hindered at Earth-surface conditions. Sedimentary organic matter transforms progressively to graphite through the loss of oxygenated functional groups, followed by aliphatic groups, and subsequent structural reorganisation 3 with the application of heat and pressure at depth within the Earth. However, once formed, graphite does not 
revert easily to a disordered state. Beyssac et al.6. 7 showed that heat is the main driving force for the crystallisation of graphite below Earth's surface. As burial depth increases, heat diffused from Earth's deep interior and from radioactive decay in the surrounding rocks provides the energy required to form graphite crystals. This is a gradual process, which is only completed when the temperature approaches $650^{\circ} \mathrm{C}$, at lower temperatures carbon remains partially disordered, although a couple of exceptions have been reported. Firstly, $\mathrm{CO}_{2}$-rich fluid can deposit graphite during hydrothermal alteration at temperatures as low as $500^{\circ} \mathrm{C}, 8$ and secondly, thin films of graphite can form on mineral faces at moderate metamorphic temperatures, leading to structural heterogeneity within a sample9. Crystallinity of graphite can be measured using Raman Spectroscopy; spectra from disordered carbon exhibit multiple broad peaks, especially at 1350 and $1600 \mathrm{~cm}^{-1}$. With increasing crystallinity, these peaks are replaced by a single, sharp peak (full-width at half-maximum as little as $15 \mathrm{~cm}^{-1}$ ) at $1580 \mathrm{~cm}^{-1} .1$ The degree of crystallinity, determined by comparing peak areas, has been correlated to the maximum temperatures experienced by the C-containing rock, as quantified by mineral assemblages. 6

Complex geological settings, such as mountain belts, contain rocks that have experienced a wide range of peak temperatures. Upon erosion, these rocks yield carbon with a commensurate range of structures. Together with sediment, eroded carbon is conveyed by rivers from erosional source areas into depositional basins. During transport, river load is thoroughly mixed so that analysis of the full range of carbon structures present in a sediment sample allows the input of each carbon type to be investigated, and insight to be gained into the geological processes to which the source rocks and their erosional products have been subjected. Eroded highly-graphitized carbonaceous material can survive fluvial and submarine transport unaltered over 1000 s of $\mathrm{km}$, and be 
re-deposited in new sedimentary formations, 10 while disordered and semigraphitized material is more prone to oxidation en-route.11.12 In smaller systems where the transport distance is an order of magnitude shorter, loss of fossil organic carbon is less pronounced 13 so that the carbon inventory of basin deposits may be representative of the pattern of erosion in the sediment source area. The mountain island of Taiwan is an example of such a small system.

Taiwan is situated at 22-23 degrees North, within the Inter-Tropical Convergence Zone, at the convergent boundary between the Asian continent and the Philippine Sea plate. In 2009 Typhoon Morakot stalled over south Taiwan, precipitating up to $3600 \mathrm{~mm}$ of monsoon-supplied water in four days and causing extensive flooding and the mobilisation and export of large quantities of sediment.14 The deposits of this exceptionally large event are rich in carbonaceous material spanning the full compositional breadth from terrestrial plant biomass to fully graphitized carbon. In order to systematically and efficiently determine the source of carbonaceous material in a large number of samples collected from Morakot's deposits and the geological formations from which these deposits were sourced, several methodological requirements must be met. The sample preparation method must ready different precursors such as bedrock, coarse-grained fluvial sediment and fine-grained offshore sediment for analysis in uniform fashion. The heterogeneous carbon species present in these samples must all be probed, with enough data collected to represent the population of carbon compounds within a single sample. Some of these carbon types may be present encased within rock fragments. Finally, having collected a large dataset there must be an automated processing system in place to analyse the spectra and report the results. In this paper we present a new method for automated analysis of carbon in powdered geological materials by Raman 
spectroscopy, and review its use in an assessment of the sourcing of carbon during typhoon Morakot.

\section{Material and Methods}

\section{Sample acquisition}

Following typhoon Morakot, we have collected samples of flood deposits in the floodplain of the Gaoping River in SW Taiwan and from the shelf and submarine canyon offshore where the river had delivered material to the sea (Fig. 1). These samples represent the wide range of metamorphic grades and lithologies exposed in the Gaoping catchment, and allow investigation of metamorphic carbon from source to sink in a tectonically active setting following an extreme climatic event. They also contain a full range of particulate organic carbon in a diverse range of geological materials, offering a suitable opportunity to test the versatility and practicality of the new approach. Offshore core samples were collected by Taiwan Research Vessel Ocean Researcher 1, during sampling cruise number 915 , using a box-coring process, in which a container of sediment is collected from the seafloor and separately cored after recovery. The exception is core $\mathrm{K} 1$, which was collected by driving a weighted tube directly into the sea floor. Cores were cut longitudinally and sub-sampled at centimetre resolution, and each sub-sample individually freeze-dried. Of this, a representative $5 \mathrm{~g}$ aliquot was collected at selected locations within the core. Meanwhile, samples of river sediments were taken beside the Gaoping main channel at the Pingtung Line railway bridge, and from two tributaries in Ligang Township. The western tributary drains mostly lowland areas and foothills underlain by sedimentary rocks of the Cholan and Tuokoshan formations. The eastern tributary drains mostly highland rock units exposed in the central mountain belt, although the location of sampling is within the lowland units. 
The central mountain belt has been sampled extensively, 15 finding a range of graphite-bearing rock units. These units contain autochthonous partially graphitized material, with detrital highly graphitized crystals reported in the Hsuehshan Range and Backbone Slates.

The Cholan and Tuokoshan formations in Western Taiwan comprise marine to terrestrial sediments of Late Pliocene / Early Pleistocene age. Hand-specimen samples were collected from outcrops exposed in a riverbed to the east of Taichung city, along-strike from the Gaoping river basin. In each case, 50-300 g of solid rock were collected.

Bedrock and fluvial sediment samples were dried overnight at $80^{\circ} \mathrm{C}$ after collection, to prevent microbial decay. Rock samples contrast with the individual sediment grains of the river, and fine mud of the offshore samples, providing a processing challenge in which each type of sample must be prepared equivalently to facilitate rapid acquisition of multiple Raman spectra of carbonaceous materials. This involves size reduction of coarser materials. Investigations of the introduction of disorder to graphite crystals by grinding in air using an agate mortar found that grinding for many hours can introduce disorder peaks at 1350 and $1620 \mathrm{~cm}^{-1} .16$ However, grinding periods of less than one hour did not significantly alter the Raman spectra of the graphite samples. Similar work17 corroborated this finding using Raman Spectroscopy, XRD and HRTEM to show that the crystallinity of high-grade graphite was unchanged after up to 120 minutes of grinding. Although neither of these papers considered changes in semi-graphitized or disordered precursor material, we have adopted a grinding approach to sample preparation in this study, and tested its effect on carbon structure. We ground dry sediment and rock samples in a PM-400 agate ball-mill grinder (Retsch) for 12 minutes at $250 \mathrm{rpm}$ (sun wheel speed), the 
standard procedure for preparation for geochemical analysis. Stainless-steel claddings on the grinding pots served to keep the material cool. After grinding the volume weighted mean particle diameter was $20 \mu \mathrm{m}$, with median diameter of $9.2 \mu \mathrm{m}$, as measured by a Mastersizer 2000 laser grain sizer (Malvern Instruments). The effect of this homogenization procedure on semi-graphitized material was assessed by comparison with un-ground equivalents, where dry sediments were placed directly onto glass slides.

\section{Raman Spectroscopy Techniques and Methods}

Graphitic carbon has been investigated using Raman spectroscopy for over 40 years. Semi-graphitized materials produce a Raman peak at $1350 \mathrm{~cm}^{-1}$, the D1 peak, which decreases in amplitude and width with increasing order.18 This peak is sensitive to excitation frequency, lowering its Raman shift with increasing incoming wavelength.19 To maintain comparability with previous studies on geological carbonaceous material,20 we have also used a 514nm Ar-ion laser to collect spectra. A further three disorder peaks, D2, D3 and D4, appear in increasingly disordered carbonaceous materials. 21. 22 The $1620 \mathrm{~cm}^{-1}$ D2 peak combines with and dominates the crystalline-graphite $\mathrm{G}$ peak $\left(1580 \mathrm{~cm}^{-1}\right)$ in highly disordered material, forming a single "G band", while the D3 and D4 peaks are minor components which sit at $1500 \mathrm{~cm}^{-1}$ and $1150-1250 \mathrm{~cm}^{-1}$ respectively in the most disordered material.

Raman spectra from sediment cores were collected using Ramascope-1000 and InVia Raman spectrometers (Renishaw). One spatula ( $0.25 \mathrm{~g})$ of material was pressed between glass slides to produce a flattened sample area with $2 \mathrm{~cm}$ diameter. This removed the depth-of-field effect of the high-magnification lens, reducing the requirement to refocus the microscope, which dominates when sampling sediment directly. Within this sample area, 10-20 flakes of 
carbonaceous material were usually visible using a 50 times magnification objective lens. Measurements were taken from each carbonaceous grain using a $514 \mathrm{~nm}$ Ar-ion laser, set to $0.75-1.8 \mathrm{~mW}$ for 30 seconds to avoid damaging the target. The open-air exposure of the graphite grains, and surrounding sediments, minimizes thermal damage to the samples; no such damage was seen during the work. Raman shift was measured from $800-3200 \mathrm{~cm}^{-1}$ using the "synchroscan" function.

\section{Peak Fitting}

Spectroscopic peaks are often fitted best using Voigt profiles, which are a combination of Lorentzian and Gaussian broadening behaviours. Gaussian profiles alone do not accommodate sufficient peak-broadening, while Lorentzian profiles can be excessively broad. A published peak-fitting method for semi- and highly-graphitized material fits Voigt profiles to three peaks: G, D1 and D2.7 A linear baseline is removed from each sample, as background intensity tends to increase with Raman shift. This technique was calibrated for CM submitted to metamorphic burial temperatures above $360^{\circ} \mathrm{C}$.

Another published fitting procedure, designed for fitting of spectra from more disordered materials, fits Lorentzian profiles to five Raman peaks, covering typical ranges for G, D1, D2, D3 and D4.22 In this procedure, Lorentzian profiles were chosen rather than Voigt profiles to reduce the degrees of freedom available when fitting, as the multi-parameter approach of Voigt fitting produced unstable fits for complex spectra. Increasingly disordered material has larger peak widths, for which the broad Lorentzian profile is a good match.

For this study, two automatic fitting routines have been created using the software "GNUPlot". The first routine is based on the Voigt fitting procedure.7 Three Voigt profiles are fitted, with a linear baseline. If required, non-linear 
equations for the baseline could be incorporated, although tuning the baseline for every individual spectrum removes some objectivity. Initial conditions are provided by sampling relevant parts of the input spectra, namely the amplitudes and locations of the $\mathrm{G}$ and D1 peaks. Initial D2 amplitude is also measured from the input spectra. The width and location parameters are then allowed to vary within certain ranges, defined in Table I, whilst amplitude is allowed to vary without limit. The Voigt profile is defined as:

$$
V x ; \sigma ; \gamma=-\infty \infty \mathrm{GX}^{\prime} ; \sigma L x-x^{\prime} ; \gamma d x^{\prime}
$$

where $G(x)$ is a Gaussian function and $L(x)$ is a Lorentzian function, $\sigma$ is the standard deviation of the Gaussian function and $y$ is the half-width at halfmaximum of the Lorentzian function. The Voigt function is computationally complicated, and GNUPlot uses a rapid approximation of the Voigt profile, accurate to one part in $10^{4} .23$ Thus the function fitted is:

$$
f x=\text { areai } \times \text { voigt }(x-\text { locationi, widthi }) i=\text { peaks } G, D 1, D 2+m x+c \text {. }
$$

The second routine fits five Lorentzian profiles.22 As before, G, D1, D2, D3 and D4 are initiated by reading from the input spectra, taking the highest amplitude in a given range and correcting for a linear baseline. The peak amplitudes are again free to vary unrestricted, while peak widths and locations are fixed within certain ranges, as defined in Table II. The equation for fitting Lorentzian profiles is:

$\mathrm{fx}=$ heightiwidthi2 $(\mathrm{x}$-locationi) $2+$ widthi2 $) \mathrm{i}=$ peaks $\mathrm{G}, \mathrm{D} 1-\mathrm{D} 4+\mathrm{mx}+\mathrm{c}$. 
Both of these procedures are able to fit spectra rapidly with minimal residual intensity (defined as the difference between the input spectra and the fit). The fitting procedure is iterated until the change in residual is less than $10^{-9}$ of the total residual intensity. The advantage of using any automated procedure for this type of analysis is twofold. Firstly the analysis requires only computation time, spectra and analysis graphs can be produced automatically if new data is collected, or if it is decided to perform the peak analysis differently. Secondly, there is no bias introduced through operator-guided detection of peaks, each spectrum has been treated in exactly the same manner. Figure 2 shows the fits produced by these two procedures. Each fitting run generates a results figure showing the fitted peaks, fitting procedure and residual signal after fitting, allowing inspection of the accuracy of the procedure.

\section{Carbon Classification}

To resolve differences within populations of graphite and disordered carbon, samples can be characterised using a variety of parameters. The R1 and R2 measurements, applied to Voigt-fitted spectra, characterise intermediate- and high-grade graphite very successfully, and have been calibrated for peak temperature using metamorphic petrology, 6 making the carbonaceous material geothermometer a useful tool.

$$
\mathrm{R} 2=\mathrm{D} 1 \text { areaGarea }+\mathrm{D} 1 \text { area }+ \text { D2area }
$$

$$
\text { Temperature }=-441 \times \mathrm{R} 2+645
$$

Whilst both ratios have been calibrated for temperature, $\mathrm{R} 2$ is the preferred metric. In samples where D1 is wide but has a low-intensity the R1 parameter 
can show a reversed trend and it is also more sensitive to the accuracy of baseline corrections and D2 fitting. R2 is particularly effective at characterising highly-crystalline material, up to perfectly-graphitized crystals with $\mathrm{T}=645^{\circ} \mathrm{C}$. However, R2 measurements saturate above $\sim 0.7$ (metamorphic temperatures below $\sim 330^{\circ} \mathrm{C}$ ). The RA2 measurement is applied to disordered materials with Lorentzian fits, but the temperature correlations are less certain. 22

\section{$\mathrm{RA} 1=\mathrm{D} 1 \mathrm{area}+\mathrm{D} 4 \mathrm{rreaGarea}+\mathrm{D} 1 \mathrm{area}+\mathrm{D} 2 \mathrm{area}+$}

\section{D3area+ D4area (7)}

\section{$\mathrm{RA} 2=\mathrm{D} 1$ area + D4areaGarea + D2area + D3area (8)}

\section{Temperature $=$ RA2-0.270.0045 (9)}

Lastly, because it has been noted that empirically, increasingly disordered material tends to have a larger total-width, 22 the full-width at half-maximum (FWHM) of the G, D1 and D2 peaks were recorded (the total-width parameter).

The fitting procedures were calibrated by comparison with a collection of spectra with known metamorphic temperatures, fitted manually using the program “PeakFit ${ }^{\circledR} ", 7,22$ covering a wide range of carbon structures. Figure 3 shows cross-plotted results for R1, R2, RA1 and RA2, with very good agreement between the manual and automatic fits. For RA1 and RA2, automated fitting results are related to manual fits with a linear 0.95:1 relationship and $R^{2}$ values in excess of 0.925 . For the Voigt procedure, R1 values correlate with a linear 1.004:1 relationship and $R^{2}=0.999$, while $R 2$ values have a 0.91:1 relationship and $R^{2}$ value of 0.991 
304 It is important that spectra are fitted with the appropriate procedure. Applying

305 the Voigt fit to disordered material, or the Lorentzian fit to highly-graphitized material, leads to poor fits and incorrect parameterisations. In order to choose the correct procedure automatically, the following workflow was implemented. In the first instance, spectra were fitted with the Voigt procedure, as this is computationally more efficient and can fit graphitized carbon as well as lowtemperature material, albeit with less precision. The results of this fit were analysed and if the R2 value was below 0.6 , and either the D1 peak width below $120 \mathrm{~cm}^{-1}$, or the R1 value was less than 0.5 , then the Voigt fit was accepted. If the fit had R2 $>0.6$, or D1 width $>120 \mathrm{~cm}^{-1}$ and $\mathrm{R} 1>0.5$ (values chosen by inspection of a range of spectra), then a Lorentzian fit was applied. Whilst R2 values of 0.65 or 0.7 can be collected from reasonably graphitized material, they can also be produced by very disordered material and thus the Lorentzian fit is applied. If the RA2 value calculated from this fit was greater than 2 (the maximum value measured in previous studies), 22 then the procedure reverted back to the Voigt fit. Finally, each spectrum was characterised using two parameters, the estimated metamorphic temperature as calculated from the R2 or RA2 value (as applicable) and total-width (the sum of the G, D1 and D2 peak widths).

This workflow leads to the identification of three groups of spectra. Spectra from highly-graphitized material have a high R2 temperature, above $360^{\circ} \mathrm{C}$. Partially graphitized and disordered materials both have low estimated temperatures, but the former has intermediate and the latter high total peak widths. Spectra fitted with the Voigt procedure have a temperature of more than $360{ }^{\circ} \mathrm{C}$ and corresponding samples have experienced significant metamorphic conditions. Values of the total width parameter (G1 + D1 + D2 widths) vary, reaching up to $250 \mathrm{~cm}^{-1}$ in these spectra. Those fitted with the Lorentzian procedure are less 
metamorphosed - published RA2 values cover temperatures as low as $200{ }^{\circ} \mathrm{C} 22$ and in some cases are little more than charcoal or lignite-grade. The total width distinguishes between these two groups. By inspection of fitting results, lowgrade metamorphic material has a total width less than $290 \mathrm{~cm}^{-1}$ while spectra collected from lignite clasts in the Plio-Pleistocene of Taiwan have total widths up to $350 \mathrm{~cm}^{-1}$. By plotting measured total width against temperature, spectra from each sample fit into one of three carbon classes. Figure 4 shows a collection of spectra from sample K1-19, just offshore Taiwan, plotted in this fashion.

Whilst less precise than the temperature-correlated area ratios and an entirely empirical parameter, the total-width metric separates very disordered material from partially-graphitized carbon. The total-width metric is not associated with a particular solid-state physical phenomenon, but it was found to be the most effective means of characterising extremely disordered material. Several other possible characterisation parameters were investigated, such as peak location and individual peak widths, but none of these were chosen due to an inability to completely separate the various carbon types present in these samples. G peak location is one possible metric, but the presence of significant D2 peaks in disordered material can limit the relevance of the G peak position. The widths of individual peaks can only be used to characterise portions of the continuum of spectra, whilst the combination of all three peaks (G, D1 and D2) allowed variation across a wider range of spectra to be identified.

\section{Results and Discussion}

\section{Effects of Grinding and the utility of sample homogenization}

Whilst pure graphite has previously been shown to be robust in grinding and lengthy fluvial transport, the disordered and partially graphitized nature of the material found in the river sediment could have made it prone to damage during 
grinding. To assess the effect of grinding on the structure and relative abundance of different types of carbonaceous material in our samples, we have compared results for ground and un-ground aliquots of samples KP2A and KP3B from the Gaoping River. Figure 5 shows a comparison of Lorentzian fitting results plotted as RA2 temperature against total width. Eight data points collected from powdered sediment have average temperature and total width values that lie within one standard deviation of the equivalent averages for five data points collected from the un-ground aliquot. Similarly, the results from sample KP3B show a matching clustering of spectrum properties for both raw and powdered materials. Both sets of spectra show a slight and statistically insignificant increase in total width after grinding, with little or no impact on the estimated temperatures. These results demonstrate that grinding has not introduced significant disorder into the samples, and we proceed assuming that this holds for all other samples in our study. Although we have not considered variable grinding times and methods we anticipate that any grinding procedure which reduces grain sizes to the $(\sim 10 \mu \mathrm{m})$ range can be applied without significant effect on the structure of carbonaceous material in geological and environmental samples.

\section{Application: Morakot flood, Taiwan}

To test the practicality of our method, we investigated the sourcing and distribution of carbonaceous material in sediments from the Gaoping canyon. We collected 201 spectra from 19 samples of sediment deposited during typhoon Morakot and rocks exposed in its source area. In general, at least ten spectra with a signal-to-noise ratio greater than three were acquired. Particles with a graphitic appearance under the microscope and a graphitic spectrum were found in five of eight samples from the Cholan and Tuokoshan formations, one of three samples from the Gaoping River and in all eight samples from the Gaoping 
submarine canyon, although the proportion of this material to other types of carbonaceous material varied greatly. Some form of disordered carbon or semigraphitized material was found in all samples, but its shape varied considerably.

Most of the Plio-Pleistocene Cholan formation samples contained highly disordered carbonaceous material (Figure 6a). Sample 17 was a $10 \times 10 \mathrm{~cm}$ piece of lignite, which still had the physical characteristics of a small log, hence we are confident that it was a piece of woody biomass that had been incorporated directly into the sediments; all spectra from this specimen had a high total width and low RA2 temperature. Six out of seven other samples from the Cholan formation contained similarly disordered carbon, creating a cluster of disordered carbon spectra at the top of Figure 6a. This is interpreted as woody material of $\mathrm{mm}$ to $\mathrm{cm}$ size incorporated into the Plio-Pleistocene sediments during deposition and subsequently transformed to lignite, indicating that the burial depths experienced by the Cholan and Tuokoshan formations were insufficient to induce metamorphism. Carbon with a higher degree of order in these formations is likely to have a bedrock source, eroded from rocks exposed in the emerging Taiwan mountain belt at the time of deposition of the Cholan and Tuokoshan sediments. There is highly-graphitized material present in six out of seven Cholan and Tuokoshan sedimentary samples and semi-graphitized material in five out of seven. Disordered carbon is much more common than semigraphitized material; samples 2, 3, 6 and 8 tend towards a bimodal distribution of highly-graphitized and disordered material. This may reflect the lesser outcrop of metamorphic rocks containing semi-graphitized carbon in the Central Range during Plio-Pleistocene times, or the loss of this carbon during exhumation and erosion of the Taiwan Mountains at this time. 
409 Figure $6 \mathrm{~b}$ shows the range of spectra collected from Gaoping River sediments,

410 the majority of which was semi-ordered material derived from a branch draining

411 the Central Mountain Range. This material has experienced moderate

412 metamorphism15 but did not approach conditions where crystalline graphite is

413 usually achieved. The only graphite grains found in the Gaoping River are from

414 the branch draining the western plains, in which the graphite-rich Cholan and

415 Tuokoshan formations crop out.

416 Offshore sediments show a range of material that is a combination of both the

417 Central Range semi-graphitized carbon and the fully-graphitized and disordered

418 carbon of the Plio-Pleistocene rocks. Semi-graphitized and highly-graphitized

419 materials were contained in all samples, including samples collected on the

420 continental shelf and the Gaoping canyon (Fig. $6 c$ and $6 \mathrm{~d}$ respectively) but the

421 shelf cores contained less disordered carbon. The abundance of disordered

material in canyon cores compared to shelf cores hints at variations in the hydrodynamic processes depositing material in these locations. The sedimentation rate on the shelf is less than $1 \mathrm{~cm} \mathrm{yr}^{-1}$, whilst the canyon deposits were sourced in a single flood event, transported by sediment gravity currents along the seafloor. This rapid transport and deposition process could entrain and bury buoyant disordered material more efficiently than the gradual raining-down of material onto the shelf from the sea surface. This indicates that the transport distance along the Gaoping Canyon system $(20-200 \mathrm{~km})$ is too short for comprehensive loss of semi-graphitized carbon by oxidation during sediment transport, in contrast to the Bengal Fan system where offshore transport pathways are an order of magnitude longer (2000 km). 


\section{Conclusions}

Grinding of sediments into a fine powder has allowed efficient collection of many hundreds of Raman spectra from a range of samples from Taiwan. This process did not introduce significant disorder into individual grains of carbon within a sample. Thus short-period grinding and spectra-collection from powder is a suitable method for quickly sampling a population of samples in a fair and thorough manner. Collected Raman spectra were analysed automatically using peak-fitting techniques based on two published procedures - five characteristic Lorentzian peaks or three Voigt peaks. Automated analysis significantly reduced the processing time and removed the possibility of human variation or bias, thus allowing easy and fair comparison of the spectra, whilst output results figures allow inspection of spectral quality and fitting accuracy. A combination of these methods allowed identification of the sources of graphite and disordered material from Taiwan to the South China Sea following typhoon Morakot.

Automatic focussing onto the sample surface, combined with a fast mapping procedure, will make spectral acquisition more efficient. The automatic processing technique is even more important in this situation, to filter out noncarbonaceous spectra. These techniques are now becoming available on spectroscopic equipment.

Acknowledgements: The authors would like to thank Olivier Beyssac for help, encouragement and spectrometer access. Robert Sparkes was funded by an EPSRC studentship, James T. Liu by grant number NSC 95-2745-M-110-001 for the FATES-HYPERS program which provided the cores in this study. 
1. B. Wopenka, J.D. Pasteris. "Structural characterization of kerogens to granulite-facies graphite - applicability of Raman microprobe spectroscopy". American Mineralogist. 1993. 78 (5-6): 533-557.

2. J.D. Pasteris, B. Wopenka. "Raman-spectra of graphite as indicators of degree of metamorphism". CANADIAN MINERALOGIST. 1991. 29 (Part 1): 1-9.

3. C.P. Marshall, H.G.M. Edwards, J. Jehlicka. “Understanding the application of Raman spectroscopy to the detection of traces of life". ASTROBIOLOGY. 2010. $10(2): 229-243$.

4. M.W.I. Schmidt, J.O. Skjemstad, C. Jager. "Carbon isotope geochemistry and nanomorphology of soil black carbon: Black chernozemic soils in central Europe originate from ancient biomass burning". GLOBAL BIOGEOCHEMICAL CYCLES. 2002. 16 (4): 1123-1131.

5. F.P. Bundy. "Pressure-temperature phase diagram of elemental carbon". Physica A: Statistical Mechanics and its Applications. 1989. 156 (1): 169 - 178.
6.
O. Beyssac,
B. Goffe, C.
C. Chopin, J.N. Rouzaud. "Raman spectra of carbonaceous material in metasediments: a new geothermometer". JOURNAL OF METAMORPHIC GEOLOGY. 2002. 20 (9): 859-871.

7. O. Beyssac, F. Brunet, J.-P. Petitet, B. Goffe, J.-N. Rouzaud. “Experimental study of the microtextural and structural transformations of carbonaceous materials under pressure and temperature". European Journal of Mineralogy. 2003. 15 (6): 937-951.

8. F. J. Luque, L. Ortega, J. F. Barrenechea, D. Millward, O. Beyssac, J-M. Huizenga. "Deposition of highly crystalline graphite from moderate-temperature fluids". GEOLOGY. 2009. 37 (3): 275-278. 
481 9. M.A. van Zuilen, D. Fliegel, R. Wirth, A. Lepland, Y. Qu, A. Schreiber, A.E.

482 Romashkin, P. Philippot. "Mineral-templated growth of natural graphite films".

483 GEOCHIMICA ET COSMOCHIMICA ACTA. 2012. 83: 252-262.

484 10. J. Jehlicka, J.N. Rouzaud. “Organic geochemistry of Precambrian shales and 485 schists (Bohemian Massif, Central-Europe)". ORGANIC GEOCHEMISTRY. 1990. 16 486 (4-6): 865, 1990. 14TH INTERNATIONAL MEETING ON ORGANIC GEOCHEMISTRY : 487 ADVANCES IN ORGANIC GEOCHEMISTRY, PARIS, FRANCE, 1989.

488 11. V. Galy, O. Beyssac, C. France-Lanord, T. Eglinton. "Recycling of graphite 489 during Himalayan erosion: A geological stabilization of carbon in the crust". 490 Science. 2008. 322 (5903): 943-945.

491

492

493

12. J. Bouchez, O. Beyssac, V. Galy, J. Gaillardet, C. France-Lanord, L. Maurice, P. Moreira-Turcq. "Oxidation of petrogenic organic carbon in the Amazon floodplain as a source of atmospheric $\mathrm{CO}_{2}{ }^{\prime \prime}$. GEOLOGY. 2010. 38 (3): 255-258.

13. R.G. Hilton, A. Galy, N. Hovius, M.-J. Horng, H. Chen. “Efficient transport of fossil organic carbon to the ocean by steep mountain rivers: An orogenic carbon sequestration mechanism". GEOLOGY. 2011. 39 (1): 71-74.

14. A. J. West, C. W. Lin, T. C. Lin, R. G. Hilton, S. H. Liu, C. T. Chang, K. C. Lin, A. Galy, R. B. Sparkes, N. Hovius. “Mobilization and transport of coarse woody debris to the oceans triggered by an extreme tropical storm". LIMNOLOGY AND OCEANOGRAPHY. 2011. 56 (1): 77-85.

\section{O. Beyssac, M. Simoes, J.P. Avouac, K.A. Farley, Yue-Gau Chen, Yu-Chang} Chan, B. Goffe. “Late Cenozoic metamorphic evolution and exhumation of Taiwan". Tectonics. 2007. 26 (6): TC6001-1-32.

16. M. Nakamizo, H. Honda, M. Inagaki. “Raman-spectra of ground natural graphite". CARBON. 1978. 16 (4): 281-283. 
17. E. Crespo, F. J. Luque, J. F. Barrenechea, M. Rodas. "Influence of grinding on graphite crystallinity from experimental and natural data: implications for graphite thermometry and sample preparation". MINERALOGICAL MAGAZINE. 2006. 70 (6): 697-707.

18. F. Tuinstra, J.L. Koenig. "Raman spectrum of graphite". Journal Of Chemical Physics. 1970. 53 (3): 1126-1130.

19. T.P. Mernagh, R.P. Cooney, R.A. Johnson. “Raman spectra of graphon carbon black". Carbon. 1984. 22 (1): $39-42$.

20. O. Beyssac, B. Goffe, J.-P. Petitet, E. Froigneux, M. Moreau, J.-N. Rouzaud. “On the characterization of disordered and heterogeneous carbonaceous materials by Raman spectroscopy". Spectrochimica Acta. 2003.59 (10): 2267 2276.

21. O. Beyssac, J.-N. Rouzaud, B. Goffe, F. Brunet, C. Chopin. “Graphitization in a high-pressure, low-temperature metamorphic gradient: a Raman microspectroscopy and HRTEM study". CONTRIBUTIONS TO MINERALOGY AND PETROLOGY. 2002. 143 (1): 19-31.

22. A. Lahfid, O. Beyssac, E. Deville, F. Negro, C. Chopin, B. Goffe. "Evolution of the Raman spectrum of carbonaceous material in low-grade metasediments of the Glarus Alps (Switzerland)". TERRA NOVA. 2010. 22 (5): 354-360.

23. R.J. Wells. "Rapid approximation to the Voigt/Faddeeva function and its derivatives". JOURNAL OF QUANTITATIVE SPECTROSCOPY \& RADIATIVE TRANSFER. 1999. 62 (1): 29-48. 
531 Table I: Peak fitting constraints used in the Voigt fitting procedure

\begin{tabular}{|l|l|l|l|l|l|l|}
\hline Peak & Initial Height & $\begin{array}{l}\text { Constraints when } \\
\text { choosing }\end{array}$ & $\begin{array}{l}\text { Initial } \\
\text { Location }\end{array}$ & Constraints & Initial Width & $\begin{array}{l}\text { Constraints } \\
\text { when fitting }\end{array}$ \\
\hline G & From data & $1575-1600 \mathrm{~cm}^{-1}$ & $\begin{array}{l}\text { From initial } \\
\text { height }\end{array}$ & $1575-1605$ & $5 \mathrm{~cm}^{-1}$ & when fitting \\
\hline D1 & From data & $1200-1450 \mathrm{~cm}^{-1}$ & From initial & $1300-1400$ & $12.7 \mathrm{~cm}^{-1}$ & $<200 \mathrm{~cm}^{-1}$ \\
532 & height & $1620 \mathrm{~cm}^{-1}$ & $1610-1625$ & $2.2 \mathrm{~cm}^{-1}$ & $<32 \mathrm{~cm}^{-1}$ \\
\hline
\end{tabular}


533 Table II: Peak fitting constraints used in the Lorentz fitting procedure

\begin{tabular}{|l|l|l|l|l|l|l|}
\hline Peak & Initial Height & $\begin{array}{l}\text { Constraints when } \\
\text { choosing }\end{array}$ & $\begin{array}{l}\text { Initial } \\
\text { Location }\end{array}$ & $\begin{array}{l}\text { Constraints } \\
\text { when fitting }\end{array}$ & Initial Width & $\begin{array}{l}\text { Constraints } \\
\text { when fitting }\end{array}$ \\
\hline G & From data & $1580-1600 \mathrm{~cm}-1$ & $\begin{array}{l}\text { From initial } \\
\text { height }\end{array}$ & $\begin{array}{l}1550-1630 \\
\mathrm{~cm}-1\end{array}$ & $17 \mathrm{~cm}-1$ & $<80 \mathrm{~cm}-1$ \\
\hline D1 & From data & $1200-1450 \mathrm{~cm}-1$ & $\begin{array}{l}\text { From initial } \\
\text { height }\end{array}$ & $\begin{array}{l}1300-1400 \\
\mathrm{~cm}-1\end{array}$ & $72 \mathrm{~cm}-1$ & $<200 \mathrm{~cm}-1$ \\
\hline D2 & From data & $1610-1640 \mathrm{~cm}-1$ & $1601 \mathrm{~cm}-1$ & $\begin{array}{l}1630-1640 \\
\mathrm{~cm}-1\end{array}$ & $17 \mathrm{~cm}-1$ & $<80 \mathrm{~cm}-1$ \\
\hline D3 & From data & $1490-1510 \mathrm{~cm}-1$ & $1500 \mathrm{~cm}-1$ & $\begin{array}{l}1475-1525 \\
\mathrm{~cm}-1\end{array}$ & $100 \mathrm{~cm}-1$ & $<200 \mathrm{~cm}-1$ \\
\hline D4 & From data & $1140-1150 \mathrm{~cm}-1$ & $1250 \mathrm{~cm}-1$ & $\begin{array}{l}1200-1250 \\
\mathrm{~cm}-1\end{array}$ & $150 \mathrm{~cm}-1$ & $<200 \mathrm{~cm}-1$ \\
\hline
\end{tabular}


535 Figure 1:

536 A map of Taiwan and the surrounding bathymetry, showing the location of

537 samples used in this study. Black circles are offshore cores, white triangles are

538 rock samples from the Cholan and Tuokoshan formations, inverted white

539 triangles are sediments from the Gaoping River. The Gaoping catchment is

540 shown in white, with the Plio-Pleistocene sedimentary formations cross-hatched.

541 Main tributaries of the Gaoping River are shown with black lines. Note that some

542 river samples are from tributaries that mostly drain the mountains of the Central

543 Range. 
545 Figure 2:

546 Examples of fits of four spectra collected from sample K1. These represent a 547 range from highly-graphitized to disordered material. Upper figures ( $a$ and b) 548 show Voigt fits, lower figures (c and d) Lorentzians. Spectra have had a linear 549 background removed automatically during fitting. The fitted peaks are shown 550 with dashed lines, the sum of these is a solid line that matches the spectra with 551 minimal residual signal. 
553 Figure 3:

554 Cross-plotting area ratio values $(a=R 1, b=R 2, c=R A 1, d=R A 2)$ from manual and 555 automated fits shows that the automated analysis procedure is a suitable 556 substitute for manual curve fitting. In each graph the best fit line is almost 557 collinear with a 1:1 relationship. 
558 Figure 4:

559 Spectra collected from sample K1-19 (19 cm depth in sediment core K1,

560 collected from the Gaoping Canyon). A linear background correction has been

561 fitted and applied to each spectrum. There are a range of carbonaceous

562 materials here: highly-graphitized (dark grey), semi-graphitized (mid grey) and

563 disordered material (light grey) plotted in total width - temperature space. Using

564 these axes to analyse large populations of spectra can easily show patterns

565 within the degree of graphitization. 
567 Figure 5:

568 A comparison of spectral properties (total-width vs. RA2 temperatures) from two

569 river sediment samples, a) before and b) after 12 minutes of ball-mill grinding.

570 The large symbols show the average value along with $1 \sigma$ error bars. In each case

571 the average results are within error of each other, suggesting that no significant

572 change in structure is introduced through grinding. 
574 Figure 6:

575 Results from four locations in Taiwan and the Gaoping canyon showing the range

576 of carbon morphologies present in these locations. The Plio-Pleistocene

577 formations (a) supply large amounts of highly-graphitized and disordered

578 material to the Gaoping. The highland branch of the Gaoping river (b) drains the

579 Central Range of Taiwan and is dominated by semi-graphitized material. Highly

580 graphitized sample comes from the western branch, draining graphite bearing

581 Plio-Pleistocene units. All three types of carbon are seen offshore, although

582 varying distributions of disordered material are seen in the Gaoping Canyon (c)

583 and continental shelf $(d)$. 